TẠP CHÍ KHOA HỌC ĐẠI HỌC TÂN TRÀO

ISSN: $2354-1431$

http://tckh.daihoctantrao.edu.vn/

RESEARCH AND TESTING OF SOME TYPES OF FRUITS MAKE A COLLECTING VEGETABLES, A YELLOW VEGETABLES AND A TYPES OF INDIVIDUALS CAUSING AGRICULTURAL PLANT

\author{
Pham Thi Mai Trang ${ }^{l, *}$, Vi Xuan Hoc ${ }^{l}$ \\ ${ }^{I}$ Tan Trao University, Vietnam \\ *Email address: maitrang.bvtvtq@gmail.com \\ http://doi.org/10.51453/2354-1431/2021/571
}

\section{Article info}

Recieved: 07/4/2021

Accepted: 05/7/2021

\section{Keywords:}

Capture bait, Golden flies, Scaly wings;

\begin{abstract}
:
In recent years, the golden fly (Tephritidae) is one of the serious harms to fruit trees, vegetables in general, and cucumbers in particular, the damage of the golden fly greatly affects the quantity and quality of the product. If the damage at high density can cause great economic damage to farmers, in order to prevent the harmful effects of the gold fly, there are many types of traps and residues on the market to collect. However, some types are at high prices, some types still have to use chemical drugs, thus affecting production costs as well as being toxic to humans and the environment. From the above reasons, this study was done to overcome the above limitations, the research results showed that: In the spring-summer season, trapping ripe pineapple fruit with a thickness of $10 \mathrm{~cm}$, collecting golden fly adults with the highest efficiency reached 189.8 individuals/trapping and capturing mature, scaly wings with the highest efficiency reaching 19.8/trap. The size of the $10 \mathrm{~cm} 2$ ripe jackfruit trap captures the tallest golden fly adult at 144.0/trap and captures the adult with the highest scalp-wing set of 15.8/trap. In the autumn-winter season, trap ripe Pineapple fruit with $10 \mathrm{~cm}$ and $5 \mathrm{~cm}$ thickness, capture mature golden fly with the highest efficiency at 202.4 individuals/trap and 177.4 individuals/trap. the highest is 20.0 individuals/trap and 15.4 individuals/trap, the ripe jackfruit trap is $10 \mathrm{~cm}^{2}$ in size, captures the highest golden fly adult 166.2/trap, captured the highest scale winged adult 14.6 individuals/trap.
\end{abstract}


TẠP CHÍ KHOA HỌC ĐẠI HỌC TÂN TRÀO

ISSN: $2354-1431$

http://tckh.daihoctantrao.edu.vn/

\title{
NGHIÊN CỨU THỬ NGHIỆM MỘT SỐ LOẠI QUẢ LÀM MỒI THU BẮT TRƯởNG THÀNH RUỒI VÀNG VÀ TRƯởNG THÀNH MỘT LOÀI THUỘC Bộ CÁNH VẢY GÂY HẠI CÂY TRỒNG NÔNG NGHIỆP
}

\author{
Phạm Thị Mai Trang ${ }^{l, *}$, Vi Xuân Học ${ }^{l}$ \\ ${ }^{I}$ Truờng Đại học Tân Trào, Việt Nam \\ *Địa chi email: maitrang.bvtvtq@gmail.com \\ http://doi.org/10.51453/2354-1431/2021/571
}

Thông tin bài viết

Ngày nhận bài: 07/4/2021

Ngày duyệt đăng: 05/7/2021

Từ khóa:

Mồi thu bắt, Ruồi vàng, Bộ cánh vẩy

\section{Tóm tắt}

Trong những năm gần đây ruồi vàng là một trong những loại gây hại nghiêm trọng đối với cây ăn quả, rau ăn quả nói chung và cây dưa chuột nói riêng, sự gây hại của ruồi vàng làm ảnh hưởng lớn đến năng suất, chất lượng của sản phẩm. Nếu gây hại ở mật độ cao có thể gây thiệt hại lớn về kinh tế của bà con nông dân, để phòng trừ tác hại của ruồi vàng hiện nay trên thị trường có nhiều loại bẫy, bã để thu bắt tuy nhiên một số loại giá thành cao, một số loại vẫn phải dùng thuốc hóa học do đó ảnh hưởng đến chi phí sản xuất cũng như độc hại cho con người và môi trường sống. Từ những lý do trên nghiên cứu này đã được thực hiện để khác phục những hạn chế nêu trên, kết quả nghiên cứu cho thấy: Trong vụ Xuân - Hè mồi bẫy quả Dứa chín với độ dày $10 \mathrm{~cm}$ thu bắt trưởng thành ruồi vàng có hiệu quả cao nhất đạt 189,8 con/bẫy và thu bắt trưởng thành bộ cánh vẩy có hiệu quả cao nhất đạt 19,8 con/bẫy. Mồi bẫy Mít chín có kích thước $10 \mathrm{~cm}^{2}$ thu bắt được trưởng thành ruồi vàng cao nhất 144,0 con/bẫy, thu bắt được trưởng thành bộ cánh vẩy cao nhất đạt 15,8 con/bẫy. Trong vụ Thu - Đông mồi bẫy quả Dứa chín với độ dày $10 \mathrm{~cm}$ và $5 \mathrm{~cm}$ thu bắt trưởng thành ruồi vàng có hiệu quả cao nhất đạt 202,4 con/bẫy và 177,4 con/bẫy, thu bắt trưởng thành bộ cánh vẩy có hiệu quả cao nhất đạt 20,0 con/bẫy và 15,4 con/bẫy, mồi bẫy Mít chín có kích thước $10 \mathrm{~cm}^{2}$ thu bắt được trưởng thành ruồi vàng cao nhất 166,2 con/bẫy, thu bắt được trưởng thành bộ cánh vẩy cao nhất đạt 14,6 con/bẫy.

\section{1. Đặt vấn đề}

Từ thời xa xưa, ngành nông nghiệp đã phải đối mặt với sự tàn phá của nhiều loài dịch hại như nấm, cỏ dại và côn trùng, dẫn đến làm giảm đáng kể sản lượng nông nghiệp. Các biện pháp hóa học để bảo vệ cây trồng chiếm lĩnh vị trí hàng đầu trong hoạt động kiểm soát dịch hại tổng hợp và các bệnh của cây trồng. Tuy nhiên thuốc trừ sâu lại tiềm ẩn những nguy cơ gây hại đến sức khỏe con người và môi trường. Mặc dù thuốc trừ sâu hóa học đã được sử dụng nhiều năm qua để kiểm soát dịch hại, nhưng một số yếu tố đang đe dọa hiệu quả của thuốc cũng như việc sử dụng liên tục loại thuốc 
này, đó là sự phát triển khả năng kháng thuốc và quy định ngừng sử dụng hoặc hủy đăng ký một số loại thuốc trừ sâu do lo ngại đến sức khỏe con người và môi trường. Do đó, việc tìm ra giải pháp phòng trừ dịch hại sinh học thay thế thuốc hóa học là yêu cầu cấp thiết.

Hiện nay có nhiều giải pháp phòng trừ sinh học được áp dụng như: Thuốc trừ sâu sinh học, sử dụng các loại chế phẩm sinh học, sử dụng côn trùng đối kháng, nấm đối kháng, trong đó việc sử dụng các loại bẫy sinh học như: bẫy Pheromon, bẫy mùi vị, bẫy mầu, để phòng trừ và thu bắt côn trùng cũng là một trong những giải pháp có hiệu quả cao. Tuy nhiên các loại bẫy côn trùng trên thị trường hiện nay có giá tương đối cao so với thuốc hóa học vì vậy chưa được người dân lựa chọn sử dụng rộng rãi trên các cây trồng mà chủ yếu mới được lựa chọn sử dụng trên một số loại cây ăn quả như: Bưởi, Ổi, $\mathrm{Na}$. Vì vậy việc nghiên cứu chế tạo bẫy sinh học thủ công, với những nguyên liệu sẵn có, chi phí thấp, nhằm mở rộng diện tích và chủng loại cây trồng phòng trừ dịch hại bằng biện pháp sử dụng bẫy sinh học là việc làm cần thiết.

2. Đối tượng, quy mô, nội dung và phương pháp nghiên cứu

\section{1. Đối tượng nghiên cúu}

Khả năng thu hút của các loại quả sử dụng làm mồi bẫy côn trùng bộ cánh vẩy, bộ 2 cánh hại cây trồng nông nghiệp. Hiệu lực của bẫy sau 1, 3, 5, 7, 14, 21 ngày đặt bẫy.

\subsection{Quy mô, đối tự̂ng nghiên cứu}

Treo 30 bẫy sinh học thủ công và 30 bẫy sản xuất công nghiệp/vụ (dạng bẫy bình nhựa treo có mồi là pheromol) trên toàn bộ diện tích trồng cây ngắn ngày tại Trung tâm TNTH\&CGCN (Dự kiến cây dưa chuột, cây đậu trạch, đậu co ve, cây cà chua)

\subsection{Nội dung nghiên cúu}

- Xác định khối lượng sử dụng làm mồi thu bắt trưởng thành ruồi vàng và trưởng thành một số loài bộ cánh vảy hại cây trồng nông nghiệp.

- Sau khi xác định dung lượng của mồi phù hợp, tiến hành đánh giá hiệu lực dẫn dụ trưởng thành ruồi vàng và trưởng thành một số loài bộ cánh vảy hại cây trồng nông nghiệp sau 1, 3, 5, 7, 14, 21 ngày đặt bẫy, so sánh hiệu lực với bẫy sản xuất công nghiệp

\subsection{Phương pháp nghiên cúu}

\subsubsection{Công thức thí nghiệm}

ĐC: Đối chứng sử dụng bẫy sinh học thương mại

CT1: Sử dụng miếng quả dứa chín (độ dày từ: $3 \mathrm{~cm}$ ) làm bẫy

CT2: Sử dụng miếng quả dứa chín (độ dày từ: $5 \mathrm{~cm}$ ) làm bẫy

CT3: Sử dụng miếng quả dứa chín (độ dày từ: $10 \mathrm{~cm})$ làm bẫy

CT4: Sử dụng miếng mít còn nguyên vỏ làm bẫy (khoảng $\left.10 \mathrm{~cm}^{2}\right)$

CT5: Sử dụng 3-4 miếng mít không có vỏ làm mồi bẫy

\subsubsection{Phương pháp làm bẫy}

a. Xác định khối lượng sử dụng làm mồi thu bắt trưởng thành ruồi vàng và trưởng thành một số loài bộ cánh vảy hại cây trồng nông nghiệp.

- Xác định loại quả làm bẫy: Căn cứ vào đặc tính sinh vật học của trưởng thành ruồi vàng, trưởng thành bộ cánh vẩy và đặc tính mùi vị của các loại quả để lựa chọn loại quả làm mồi.

- Xác định khối lượng quả làm mồi bẫy: Lựa chọn dứa có màu vàng, mít chín có mùi thơm làm mồi bẫy

Dứa: cắt ngang quả thành các miếng mỏng có độ dày từ: $3 \mathrm{~cm}, 5 \mathrm{~cm}, 10 \mathrm{~cm}$.

Mít: Loại thứ nhất, cắt miếng mít thành các miếng nhỏ $10 \mathrm{~cm}^{2}$ bao gồm cả vỏ, sơ và múi mít; loại thứ 2 bóc rời từng múi mít riêng rẽ.

Đặt mỗi miếng của từng loại quả vào bẫy đã chuẩn bị rồi treo trên cọc sắt, chiều cao cọc từ mặt luống là $1,5 \mathrm{~m}$, các bẫy được sắp xếp trên ruộng thí nghiệm tại 5 điểm chéo góc.

b. Đánh giá hiệu lực dẫn dụ côn trùng bộ cánh vẩy, bộ 2 cánh hại cây trồng nông nghiệp của bẫy sau 1, 3, 5, 7, 14, 21 ngày đặt bẫy, so sánh hiệu lực với bẫy công nghiệp (các mốc ngày điều tra thu bắt tính hiệu quả được áp dụng theo quy định TCCS 119:2014/BVTV ban hành kèm quyết định số 1236/QĐ-BVTV-KH ngày 31/7/2014 của Cục trưởng cục $\mathrm{BVTV})$. Xác định tỷ lệ côn trùng vào bẫy sau 1, 3, 5, 7, 14, 21 ngày đặt bẫy để đánh giá hiệu lực dẫn dụ côn trùng của từng công thức. Thời điểm thu bắt côn trùng cố định vào 8 giờ sáng của các ngày $1,3,5,7,14,21$ đặt bẫy. 


\section{c. Cách làm bẫy}

Nguyên liệu: Nilon trắng kích thước $60 \mathrm{~cm} \mathrm{x}$ $80 \mathrm{~cm}$, Rổ nhựa có đường kính $30 \mathrm{~cm}$, Bình nhựa có đường kính $20 \mathrm{~cm}$, Băng dính trăng, kéo, dao, dây cao su, dây dứa, Cọc sắt cao $1.70 \mathrm{~m}$ có hàn thanh ngang trên đầu để treo bẫy.

\section{Cách làm:}

- Cắt 1 ô nhỏ trên thành bình nhựa, vị trí cách đáy bình $3 \mathrm{~cm}$, kích thước ô $10 \times 10 \mathrm{~cm}$, dùng băng dính trắng dán miếng nilon thành ống tròn vừa với kích thước bình nhựa, sau đó chụp phần nilon lên bình nhựa đến sát mép trên ô nhỏ đã cắt, dùng băng dính trắng dán cố định mép nilon vào thành bình nhựa, buộc dây thép nhỏ vào giữa đáy rổ nhựa (chiều dài dây sắt $50 \mathrm{~cm}$ ), sau đó úp ngược rổ nhựa và lồng rổ nhựa vào ống nilon, khoảng cách giữa rổ nhựa và miệng bình nhựa là $5 \mathrm{~cm}$, sau đó dùng dây cao su buộc kín đầu ống nilon (để tránh nước mưa rơi vào mồi bẫy)

- Đặt mồi vào đáy bình nhựa qua ô nhỏ đã cắt, sau đó treo bẫy lên cọc sắt bằng dây thép đã buộc vào rổ nhựa.

d. Phương pháp điều tra mật độ sâu hại trước khi đặt bẫy

Thực hiện theo phương pháp điều tra sâu bệnh hại tại quy chuẩn 01-169:2014 BNNPTNT.
- Ruộng điều tra: đối với vùng không chuyên canh: Chọn khu ruộng có diện tích từ 0,5 ha đại diện cho các yếu tố điều tra.

- Điểm điều tra: Mỗi yếu tố điều tra 10 điểm ngẫu nhiên hoặc phân bố ngẫu nhiên trên đường chéo của khu vực điều tra. Điểm điều tra phải cách bờ ít nhất 2 mét

- Cách điều tra - Ngoài đồng Quan sát từ xa đến gần, sau đó đếm trực tiếp số lượng sâu từng pha phát dục của sâu có trên từng cây trong điểm điều tra.

Công thức tính:

$$
\text { Mật độ } \operatorname{sâu}\left(\operatorname{con} / \mathrm{m}^{2}\right)=\frac{\text { Tổng số sâu điều tra }}{\text { Tống số } \mathrm{m}^{2} \text { điều tra }}
$$

Bẫy được treo trong diện tích thí nghiệm theo 5 điểm chéo góc, phải điều tra mật độ sâu hại trước khi treo bẫy để có căn cứ tính hiệu lục của bẫy.

\section{Kết quả nghiên cứu}

\subsection{Xác định dung lự̛ng mẫu sử dụng làm} mồi bẫy ruồi vàng, truởng thành côn trùng cánh vẩy

Để xác định dung lượng mẫu phù hợp nhất chúng tôi tiến hành các thí nghiệm trong vụ Xuân Hè và vụ Thu - Đông, kết quả được thể hiện tại bảng 01 và bảng 02 như sau:

Bảng 01: Thử nghiệm xác định khối lượng mồi phù họ̣p để thu bắt ruồi vàng, trưởng thành côn trùng

\begin{tabular}{|c|c|c|c|c|c|c|c|c|}
\hline \multirow{2}{*}{ TT } & \multirow{2}{*}{$\begin{array}{l}\text { Công } \\
\text { thức }\end{array}$} & \multicolumn{7}{|c|}{ Ngày theo dõi } \\
\hline & & 1 & 3 & 5 & 7 & 9 & 11 & 13 \\
\hline 1 & CT1 & \multirow{3}{*}{$\begin{array}{c}\text { Miếng } \\
\text { mồi } \\
\text { tươii, có } \\
\text { màu } \\
\text { vàng } \\
\text { sáng có } \\
\text { côn } \\
\text { trùng } \\
\text { bay } \\
\text { vào } \\
\text { bẫy }\end{array}$} & $\begin{array}{c}\text { Mồi chảy } \\
\text { nước, có } \\
\text { màu vàng } \\
\text { đậm, có côn } \\
\text { trùng bay } \\
\text { vào bẫy }\end{array}$ & $\begin{array}{l}\text { Mồi thối nhũn, } \\
\text { chảy nước, biến } \\
\text { màu đen, có ít } \\
\text { côn trùng bay } \\
\text { vào bẫy }\end{array}$ & $\begin{array}{c}\text { Mồi thối hỏng, } \\
\text { không có côn } \\
\text { trùng bay vào } \\
\text { bẫy }\end{array}$ & - & - & - \\
\hline 2 & CT2 & & $\begin{array}{c}\text { Mồi chảy } \\
\text { nước, có } \\
\text { màu vàng } \\
\text { đậm, có côn } \\
\text { trùng bay } \\
\text { vào bẫy }\end{array}$ & $\begin{array}{c}\text { Mồi chảy nước, } \\
\text { cơ bản chuyển } \\
\text { màu vàng nâu, } \\
\text { có côn trùng bay } \\
\text { vào bẫy }\end{array}$ & $\begin{array}{l}\text { Mồi thối nhũn, } \\
\text { chảy nước, } \\
\text { biến màu đen, } \\
\text { có ít côn trùng } \\
\text { bay vào bẫy }\end{array}$ & $\begin{array}{c}\text { Mồi thối hỏng, } \\
\text { không có côn } \\
\text { trùng bay vào } \\
\text { bẫy }\end{array}$ & - & - \\
\hline 3 & CT3 & & $\begin{array}{l}\text { Mồi có màu } \\
\text { vàng đậm, } \\
\text { có côn trùng } \\
\text { bay vào bâ̂y }\end{array}$ & $\begin{array}{c}\text { Mồi chảy nước, } \\
\text { bề mặt chuyển } \\
\text { màu vàng nâu, } \\
\text { có côn trùng bay } \\
\text { vào bẫy }\end{array}$ & $\begin{array}{l}\text { Mồi thối nhũn, } \\
\text { chảy nước, bề } \\
\text { mặt biến màu } \\
\text { đen, có côn } \\
\text { trùng bay vào } \\
\text { bẫy }\end{array}$ & $\begin{array}{c}\text { Mồi thối nhũn, } \\
\text { chảy nước, } \\
\text { biến màu đen, } \\
\text { có côn trùng } \\
\text { bay vào bẫy }\end{array}$ & $\begin{array}{l}\text { Mồi thối nhũn, } \\
\text { chảy nước, biến } \\
\text { màu đen, có ít } \\
\text { côn trùng bay } \\
\text { vào bẫy }\end{array}$ & $\begin{array}{c}\text { Mồi thối } \\
\text { hỏng, không } \\
\text { có côn trùng } \\
\text { bay vào bẫy }\end{array}$ \\
\hline
\end{tabular}
cánh vẩy vụ Xuân - Hè 2020 (thời điểm thử nghiệm từ 02/4 đến 23/4/2020) 


\begin{tabular}{|c|c|c|c|c|c|c|c|c|}
\hline \multirow{2}{*}{ TT } & \multirow{2}{*}{$\begin{array}{l}\text { Công } \\
\text { thức }\end{array}$} & \multicolumn{7}{|c|}{ Ngày theo dõi } \\
\hline & & 1 & 3 & 5 & 7 & 9 & 11 & 13 \\
\hline 4 & CT4 & & $\begin{array}{l}\text { Mồi có màu } \\
\text { vàng đậm, } \\
\text { có côn trùng } \\
\text { bay vào bẫy }\end{array}$ & $\begin{array}{c}\text { Mồi chảy nước, } \\
\text { có côn trùng bay } \\
\text { vào bẫy }\end{array}$ & $\begin{array}{l}\text { Mồi thối, chảy } \\
\text { nước, biến màu } \\
\text { có côn trùng } \\
\text { bay vào bẫy }\end{array}$ & $\begin{array}{c}\text { Mồi thối nhũn, } \\
\text { chảy nước, } \\
\text { biến màu đen, } \\
\text { có ít côn trùng } \\
\text { bay vào bẫy }\end{array}$ & $\begin{array}{c}\text { Mồi thối hỏng, } \\
\text { không có côn } \\
\text { trùng bay vào bẫy }\end{array}$ & - \\
\hline 5 & CT5 & & $\begin{array}{c}\text { Mồi bị chẩy } \\
\text { nước, có } \\
\text { màu vàng } \\
\text { đậm, có côn } \\
\text { trùng bay } \\
\text { vào bẫy }\end{array}$ & $\begin{array}{l}\text { Mồi thối, chảy } \\
\text { nước, biến màu } \\
\text { đen, có côn trùng } \\
\text { bay vào bẫy }\end{array}$ & $\begin{array}{c}\text { Mồi thối hỏng, } \\
\text { không có côn } \\
\text { trùng bay vào } \\
\text { bẫy. }\end{array}$ & & & - \\
\hline
\end{tabular}

Bảng 02: Thử nghiệm xác định khối lượng mồi phù hợp để thu bắt ruồi vàng, trưởng thành côn trùng cánh vẩy vụ Thu - Đông 2020 (từ 03/9 đến 24/9/2020)

\begin{tabular}{|c|c|c|c|c|c|c|c|c|c|c|}
\hline \multirow{2}{*}{ TT } & \multirow{2}{*}{$\begin{array}{l}\text { Công } \\
\text { thức }\end{array}$} & \multicolumn{9}{|c|}{ Ngày theo dõi } \\
\hline & & 1 & 3 & 5 & 7 & 9 & 11 & 13 & 15 & 17 \\
\hline 1 & CT1 & \multirow{3}{*}{$\begin{array}{c}\text { Miếng } \\
\text { mồi } \\
\text { tười, } \\
\text { có } \\
\text { màu } \\
\text { vàng } \\
\text { sáng } \\
\text { có } \\
\text { côn } \\
\text { trùng } \\
\text { bay } \\
\text { vào } \\
\text { bẫy }\end{array}$} & $\begin{array}{c}\text { Mồi chảy } \\
\text { nước, có } \\
\text { màu vàng } \\
\text { đậm, có } \\
\text { côn trùng } \\
\text { bay vào } \\
\text { bẫy }\end{array}$ & $\begin{array}{c}\text { Mồi thối } \\
\text { nhũn có } \\
\text { màu vàng } \\
\text { đen, có côn } \\
\text { trùng bay } \\
\text { vào bẫy }\end{array}$ & $\begin{array}{l}\text { Mồi thối } \\
\text { nhũn, chảy } \\
\text { nước, biến } \\
\text { màu đen, } \\
\text { có ít côn } \\
\text { trùng bay } \\
\text { vào bẫy }\end{array}$ & $\begin{array}{l}\text { Mồi thối } \\
\text { hỏng, } \\
\text { không có } \\
\text { côn trùng } \\
\text { bay vào } \\
\text { bẫy }\end{array}$ & & - & - & - \\
\hline 2 & CT2 & & $\begin{array}{c}\text { Mồi chảy } \\
\text { nước, có } \\
\text { màu vàng } \\
\text { đậm, có } \\
\text { côn trùng } \\
\text { bay vào } \\
\text { bẫy }\end{array}$ & $\begin{array}{c}\text { Mồi chảy } \\
\text { nước, cơ } \\
\text { bản chuyển } \\
\text { màu vàng } \\
\text { nâu, có côn } \\
\text { trùng bay } \\
\text { vào bẫy }\end{array}$ & $\begin{array}{c}\text { Mồi thối } \\
\text { nhũn cơ } \\
\text { bản biến } \\
\text { màu đen } \\
\text { có côn } \\
\text { trùng bay } \\
\text { vào bẫy }\end{array}$ & $\begin{array}{l}\text { Mồi thối } \\
\text { nhũn, chảy } \\
\text { nước, biến } \\
\text { màu đen, } \\
\text { có ít côn } \\
\text { trùng bay } \\
\text { vào bẫy }\end{array}$ & $\begin{array}{c}\text { Mồi } \\
\text { thối } \\
\text { hỏng, } \\
\text { không } \\
\text { có côn } \\
\text { trùng } \\
\text { bay } \\
\text { vào } \\
\text { bẫy }\end{array}$ & - & - & - \\
\hline 3 & CT3 & & $\begin{array}{c}\text { Mồi có } \\
\text { màu vàng } \\
\text { đậm, có } \\
\text { côn trùng } \\
\text { bay vào } \\
\text { bẫy }\end{array}$ & $\begin{array}{l}\text { Mồi chảy } \\
\text { nước, bề } \\
\text { mặt chuyển } \\
\text { màu vàng } \\
\text { nâu, có côn } \\
\text { trùng bay } \\
\text { vào bẫy }\end{array}$ & $\begin{array}{c}\text { Mồi thối } \\
\text { nhũn, chảy } \\
\text { nước, bề } \\
\text { mặt biến } \\
\text { màu đen, } \\
\text { có côn } \\
\text { trùng bay } \\
\text { vào bẫy }\end{array}$ & $\begin{array}{l}\text { Mồi thối } \\
\text { nhũn, chảy } \\
\text { nước, cơ } \\
\text { bản biến } \\
\text { màu đen, } \\
\text { có côn } \\
\text { trùng bay } \\
\text { vào bẫy }\end{array}$ & $\begin{array}{c}\text { Mồi } \\
\text { thối } \\
\text { nhũn, } \\
\text { chảy } \\
\text { nước, } \\
\text { biến } \\
\text { màu } \\
\text { đen, có } \\
\text { ít côn } \\
\text { trùng } \\
\text { bay } \\
\text { vào } \\
\text { bẫy }\end{array}$ & $\begin{array}{c}\text { Mồi } \\
\text { thối } \\
\text { hỏng, } \\
\text { có ít } \\
\text { côn } \\
\text { trùng } \\
\text { bay } \\
\text { vào } \\
\text { bẫy }\end{array}$ & $\begin{array}{c}\text { Mồi } \\
\text { thối } \\
\text { hỏng, } \\
\text { có ít } \\
\text { côn } \\
\text { trùng } \\
\text { bay } \\
\text { vào } \\
\text { bẫy }\end{array}$ & $\begin{array}{c}\text { Mồi } \\
\text { thối } \\
\text { hỏng, } \\
\text { không } \\
\text { có côn } \\
\text { trùng } \\
\text { bay } \\
\text { vào } \\
\text { bẫy }\end{array}$ \\
\hline
\end{tabular}




\begin{tabular}{|c|c|c|c|c|c|c|c|c|c|c|}
\hline \multirow{2}{*}{ TT } & \multirow{2}{*}{$\begin{array}{l}\text { Công } \\
\text { thức }\end{array}$} & \multicolumn{9}{|c|}{ Ngày theo dõi } \\
\hline & & 1 & 3 & 5 & 7 & 9 & 11 & 13 & 15 & 17 \\
\hline 4 & CT4 & & $\begin{array}{c}\text { Mồi có } \\
\text { màu vàng } \\
\text { đậm, có } \\
\text { côn trùng } \\
\text { bay vào } \\
\text { bẫy }\end{array}$ & $\begin{array}{l}\text { Mồi chảy } \\
\text { nước, có } \\
\text { côn trùng } \\
\text { bay vào bẫy }\end{array}$ & $\begin{array}{l}\text { Mồi thối, } \\
\text { chảy nước, } \\
\text { biến màu, } \\
\text { có côn } \\
\text { trùng bay } \\
\text { vào bẫy }\end{array}$ & $\begin{array}{l}\text { Mồi thối } \\
\text { nhũn, chảy } \\
\text { nước, biến } \\
\text { màu đen, } \\
\text { có côn } \\
\text { trùng bay } \\
\text { vào bẫy }\end{array}$ & $\begin{array}{l}\text { Mồi } \\
\text { thối } \\
\text { hỏng, } \\
\text { có ít } \\
\text { côn } \\
\text { trùng } \\
\text { bay } \\
\text { vào } \\
\text { bẫy }\end{array}$ & $\begin{array}{c}\text { Mồi } \\
\text { thối } \\
\text { hỏng, } \\
\text { không } \\
\text { có côn } \\
\text { trùng } \\
\text { bay } \\
\text { vào } \\
\text { bẫy }\end{array}$ & - & - \\
\hline 5 & CT5 & & $\begin{array}{c}\text { Mồi bị } \\
\text { chẩy } \\
\text { nước, có } \\
\text { màu vàng } \\
\text { đậm, có } \\
\text { côn trùng } \\
\text { bay vào } \\
\text { bẫy }\end{array}$ & $\begin{array}{c}\text { Mồi bắt đầu } \\
\text { thối khô } \\
\text { không còn } \\
\text { hình dạng } \\
\text { ban đầu, có } \\
\text { côn trùng } \\
\text { bay vào bẫy }\end{array}$ & $\begin{array}{l}\text { Mồi thối, } \\
\text { chảy nước, } \\
\text { biến màu } \\
\text { đen, có côn } \\
\text { trùng bay } \\
\text { vào bẫy }\end{array}$ & $\begin{array}{l}\text { Mồi thối } \\
\text { hỏng, } \\
\text { không có } \\
\text { côn trùng } \\
\text { bay vào } \\
\text { bẫy- }\end{array}$ & & - & - & - \\
\hline
\end{tabular}

Qua kết quả theo dõi tại bảng 01 và bảng 02 cho thấy:

- Trong vụ Xuân - Hè tại thời điểm thí nghiệm cuối tháng 4 đầu tháng 5/2020 nhiệt độ trung bình cao hơn vụ Thu - Đông nên thời gian thối hỏng của mồi nhanh hơn (bảng nhiệt độ các tháng thí nghiệm tại phụ lục 1). Cụ thể:

+ Vụ Xuân- Hè: CT1, CT 5 hiệu lực kéo dài đến hết ngày thứ $6, \mathrm{CT} 2$ hiệu lực kéo dài đến hết ngày thứ 8, CT4 hiệu lực kéo dài đến hết ngày thứ 10 và CT3 hiệu lực kéo dài đến hết ngày thứ 15 .

+ Vụ Thu - Đông: CT1, CT 5 hiệu lực kéo dài đến hết ngày thứ $8, \mathrm{CT} 2$, hiệu lực kéo dài đến hết ngày thứ 10 CT4 hiệu lực kéo dài đến hết ngày thứ 12 và CT3 hiệu lực kéo dài đến hết ngày thứ 16 .
Từ kết quả theo dõi ở 2 vụ chúng tôi lựa chọn CT2, CT3, CT4 để tiếp tục tiến thành thí nghiệm theo dõi hiệu lực thu bắt côn trùng.

3.2. Hiệu lục thu bắt trưởng thành Ruồi vàng, của mồi bẫy quả mít và quả dúa trên cây dua chuột

3.2.1. Hiệu lực thu bắt truởng thành Ruồi vàng, Vu Xuân-Hè 2020

Để tính được hiệu lực của bẫy chúng tôi tiến hành đặt bẫy theo 5 điểm chéo góc tại mỗi điểm đặt 01 bẫy thủ công và 01 bẫy công nghiệp, mỗi bẫy cách nhau $4 \mathrm{~m}$, sau 1, 3, 5, 7, 9, 15, 21 ngày đặt bẫy, tiến hành thu côn trùng vào bẫy và chuyển mồi bẫy sang bẫy mới để tiếp tục theo dõi thu bắt vào những ngày quy định. Kết quả thu bắt trưởng thành ruồi vàng vụ Xuân - Hè 2020 trên cây dưa chuột được thể hiện tại bảng 03 như sau:

Bảng 3: Hiệu lực Hiệu lực thu bắt trưởng thành Ruồi vàng, Vụ Xuân - Hè 2020 (thời điểm đặt bẫy từ 28/4-17/5)

\begin{tabular}{|c|c|c|c|c|c|c|c|c|c|c|}
\hline \multirow{2}{*}{ TT } & \multirow{2}{*}{$\begin{array}{c}\text { Công } \\
\text { thức }\end{array}$} & $\begin{array}{c}\text { Mật độ trước } \\
\text { khi đặt bẫy } \\
\left(\mathrm{con}^{2} \mathrm{~m}^{2}\right)\end{array}$ & \multicolumn{6}{|c|}{ Số ruồi vàng thu được sau các ngày đặt bẫy (con/bẫy) } & \multirow{2}{*}{$\begin{array}{c}\text { Tổng } \\
\text { cộng }\end{array}$} \\
\cline { 5 - 12 } & & 5,2 & 3 & 5 & 7 & 9 & 15 & 21 & \\
\hline 1 & ĐC & 51,2 & 56,8 & 43,8 & 38,4 & 31,2 & 23,4 & 15,6 & 260,4 \\
\hline 3 & CT2 & 5,2 & 41,4 & 42,6 & 33,4 & 11,6 & 5,4 & 0 & 0 & 134,4 \\
\hline 4 & CT3 & 5,2 & 42,6 & 44,2 & 40,6 & 32,8 & 21,4 & 8,2 & 0 & 189,8 \\
\hline 5 & CT4 & 5,2 & 40,8 & 44,4 & 36,4 & 16,0 & 6,4 & 0 & 0 & 144,0 \\
\hline
\end{tabular}


Qua số liệu bảng 3 cho thấy:

- Về thời gian hiệu lực của mồi

+ Đối với công thức ĐC thời gian hiệu lực kéo dài đến hết 21 ngày theo dõi, theo khuyến cáo vụ Xuân Hè thời gian hiệu lực bẫy kéo dài 4 tuần (28-30 ngày).

+ Đối với các công thức thí nghiệm, CT3 có thời gian hiệu lực dài nhất 15 ngày $\mathrm{CT} 2$ và $\mathrm{CT} 4$ có thời gian hiệu lực bằng nhau là 9 ngày.

- Về hiệu lực thu bắt của mồi

+ Đối với công thức ĐC: Tổng số ruồi vàng được TB là 260,4 con/bẫy. Hiệu lực thu bắt cao nhất sau 3 ngày đặt bẫy và giảm dần đều qua các ngày theo dõi tiếp theo. (phù hợp với thông tin khuyến cáo của nhà sản xuất)

+ Đối với các công thức thí nghiệm: Tổng số ruồi vàng thu được $\mathrm{TB}$ của $\mathrm{CT} 3$ là cao nhất đạt 189,8 con/bẫy, tiếp theo là CT4 đạt 144,0 con/bẫy, CT2 thấp nhất đạt 134,4 con/bẫy. Hiệu lực thu bắt của cả $3 \mathrm{CT}$ đều cao nhất sau 3 ngày đặt bẫy, và giảm ở những ngày theo dõi tiếp theo, trong đó CT2, CT4 hiệu lực giảm mạnh sau 5 ngày đặt bẫy còn CT3 sau 9 ngày hiệu lực mới giảm mạnh.

3.2.2. Hiệu lực thu bắt trương thành Ruồi vàng, Vu Thu - Đông 2020

Bảng 4: Hiệu lực thu bắt trưởng thành Ruồi vàng, Vụ Thu - Đông 2020 (thời điểm đặt bẫy từ 01/10-22/10)

\begin{tabular}{|c|c|c|c|c|c|c|c|c|c|c|}
\hline \multirow{2}{*}{ TT } & \multirow{2}{*}{$\begin{array}{c}\text { Công } \\
\text { thức }\end{array}$} & $\begin{array}{c}\text { Mật độ trước } \\
\text { khi đặt bẫy } \\
\left(\mathrm{con} / \mathrm{m}^{2}\right)\end{array}$ & \multicolumn{6}{|c|}{ Số ruồi vàng thu được sau các ngày đặt bẫy (con/bẫy) } & \multirow{2}{*}{ Tổng } \\
\cline { 5 - 12 } & & & 3 & 5 & 7 & 9 & 15 & 21 & cộng \\
\hline 1 & ĐC & 4.8 & 45,2 & 47,6 & 42,4 & 39,2 & 31,4 & 27,2 & 19,4 & 252,4 \\
\hline 3 & CT2 & 4.8 & 39,6 & 41,2 & 35,6 & 30,6 & 21,6 & 8,8 & 0 & 177,4 \\
\hline 4 & CT3 & 4.8 & 37,2 & 40,2 & 35,6 & 34,4 & 29,4 & 18,2 & 7,4 & 202,4 \\
\hline 5 & CT4 & 4.8 & 36,4 & 40,6 & 37,2 & 27,2 & 16,6 & 8,2 & 0 & 166,2 \\
\hline
\end{tabular}

Qua số liệu bảng 4 cho thấy:

- Về thời gian hiệu lực của mồi

+ Đối với công thức ĐC thời gian hiệu lực kéo dài đến hết 21 ngày theo dõi, theo khuyến cáo vụ Xuân Hè thời gian hiệu lực bẫy kéo dài 6 tuần (40-42 ngày).

+ Đối với các công thức thí nghiệm, CT3 có thời gian hiệu lực dài nhất 21 ngày $\mathrm{CT} 2$ và $\mathrm{CT} 4$ có thời gian hiệu lực bằng nhau là 15 ngày.

- Về hiệu lực thu bắt của mồi

+ Đối với công thức ĐC: Tổng số ruồi vàng được TB là 252,4 con/bẫy. Hiệu lực thu bắt cao nhất sau 3 ngày đặt bẫy và giảm dần đều qua các ngày theo dõi tiếp theo. (phù hợp với thông tin khuyến cáo của nhà sản xuất)
+ Đối với các công thức thí nghiệm: Tổng số ruồi vàng thu được $\mathrm{TB}$ của $\mathrm{CT} 3$ là cao nhất đạt 202,4 con/bẫy, tiếp theo là CT2 đạt 177,4 con/bẫy, CT4 thấp nhất đạt 166,2 con/bẫy. Hiệu lực thu bắt của cả $3 \mathrm{CT}$ đều cao nhất sau 3 ngày đặt bẫy, và giảm ở những ngày theo dõi tiếp theo.

Trong vụ này, mồi sử dụng bằng mít hiệu lực không cao bằng vụ xuân hè, nguyên nhân do vụ này mít sử dụng mít trái vụ chuyển từ miền nam ra, hương vị không mạnh như mít vụ Xuân - Hè là mít địa phương. Dẫn đến khả năng dẫn dụ không cao.

\subsection{Hiệu lục thu bắt trưởng thành bộ cánh} vẩy, của mồi bẫy quả mít và quả dứa trên cây dua chuột

3.3.1. Hiệu lực thu bắt trương thành bộ cánh vẩy, Vu Xuân-Hè 2020

Bảng 5: Hiệu lực thu bắt trưởng thành bộ cánh vẩy, Vụ Xuân - Hè 2020 (thời điểm đặt bẫy từ 28/4-17/5)

\begin{tabular}{|c|c|c|c|c|c|c|c|c|c|}
\hline \multirow[t]{2}{*}{ TT } & \multirow[t]{2}{*}{ Công thức } & \multicolumn{7}{|c|}{$\begin{array}{l}\text { Số trưởng thành bộ cánh vẩy thu được sau các ngày đặt bẫy } \\
\qquad(\text { con/bẫy) }\end{array}$} & \multirow{2}{*}{$\begin{array}{l}\text { Tổng } \\
\text { cộng }\end{array}$} \\
\hline & & 1 & 3 & 5 & 7 & 9 & 15 & 21 & \\
\hline 1 & ĐC & 3,2 & 9,4 & 7,2 & 6,6 & 4,2 & 3,2 & 2,2 & 36,0 \\
\hline 3 & CT2 & 5,2 & 4,8 & 1,8 & 1.2 & 0 & 0 & 0 & 13,0 \\
\hline
\end{tabular}




\begin{tabular}{|c|c|c|c|c|c|c|c|c|c|}
\hline \multirow{2}{*}{ TT } & \multirow{2}{*}{ Công thức } & \multicolumn{6}{|c|}{ Số trưởng thành bộ cánh vẩy thu được sau các ngày đặt bẫy } & \multirow{2}{*}{$\begin{array}{c}\text { Tổng } \\
\text { (con/bẫy) }\end{array}$} \\
\cline { 3 - 10 } & & $\mathbf{1}$ & $\mathbf{3}$ & $\mathbf{5}$ & $\mathbf{7}$ & $\mathbf{9}$ & $\mathbf{1 5}$ & $\mathbf{2 1}$ & \\
\hline 4 & CT3 & 5,4 & 6,2 & 4.2 & 2,6 & 0,8 & 0 & 0 & 19,8 \\
\hline 5 & CT4 & 5,2 & 5,8 & 3.4 & 1,4 & 0 & 0 & 0 & 15,8 \\
\hline
\end{tabular}

- Đối với công thức đối chứng: sử dụng loại bẫy pheromol dẫn dụ trưởng thành đực đối với trưởng thành bộ cánh vẩy, tổng số trưởng thành bộ cánh vẩy thu được là $36,0 \mathrm{con} /$ bẫy. Thành phần vào bẫy chủ yếu là trưởng thành sâu khoang, và sâu xám, hiệu lực cao nhất 3 ngày sau đặt và hiệu lực giảm dần đều qua các ngày điều tra.
- Đối với công thức thí nghiệm: CT3 là công thức thu bắt được nhiều nhất 19,8 con/bẫy, tiếp đến là CT4 15,8 con/bẫy và thấp nhất là $C T 2$ với 13,0 con/bẫy.

3.3.2. Hiệu lực thu bắt truởng thành bộ cánh vẩy, Vu Thu - Đông 2020

\section{Bảng 6: Hiệu lực thu bắt trưởng thành bộ cánh vẩy, Vụ Thu - Đông 2020 (thời điểm đặt bẫy từ 01/10-22/10)}

\begin{tabular}{|c|c|c|c|c|c|c|c|c|c|}
\hline \multirow{2}{*}{ TT } & \multirow{2}{*}{ Công thức } & \multicolumn{7}{|c|}{ Số trưởng thành bộ cánh vấy thu được sau các ngày đặt bẫy } & \multirow{2}{*}{ Tổng cộng } \\
\cline { 3 - 11 } & & 1 & 3 & 5 & 7 & 9 & 15 & 21 & \\
\hline 1 & ĐC & 3,6 & 7,2 & 6,6 & 6,2 & 4,2 & 2,8 & 2,0 & 32,6 \\
\hline 3 & CT2 & 5,0 & 4,8 & 3,2 & 1,6 & 0,8 & 0 & 0 & 15,4 \\
\hline 4 & CT3 & 5,0 & 5,6 & 4.0 & 2,8 & 1,8 & 0,8 & 0 & 20,0 \\
\hline 5 & CT4 & 5,2 & 4,4 & 3.8 & 1,2 & 0,2 & 0 & 0 & 14,6 \\
\hline
\end{tabular}

- Đối với công thức đối chứng: tổng số trưởng thành bộ cánh vẩy thu được là 32,6 con/ bẫy. Thành phần vào bẫy chủ yếu là trưởng thành sâu khoang, và sâu xám, hiệu lực cao nhất 3 ngày sau đặt và hiệu lực giảm dần đều qua các ngày điều tra.

- Đối với công thức thí nghiệm: CT3 là công thức thu bắt được nhiều nhất 20,0 con/bẫy, tiếp đến là CT2 15,4 con/bẫy và thấp nhất là $\mathrm{CT} 4$ với 14,6 con/bẫy.

\section{Kết luận}

- Trong vụ Xuân - Hè. Mồi Mít chín kích thước $10 \mathrm{~cm}^{2}$ và Dứa chín dày $10 \mathrm{~cm}$ có thời gian hiệu lực và hiệu quả thu bắt cao nhất, cụ thể.

Mồi bẫy quả Dứa chín với độ dày $10 \mathrm{~cm}$ thu bắt trưởng thành ruồi vàng có hiệu quả cao nhất đạt 189,8 con/bẫy và thu bắt trưởng thành bộ cánh vẩy có hiệu quả cao nhất đạt 19,8 con/bẫy.

Mồi bẫy mít chín có kích thước $10 \mathrm{~cm}^{2}$ thu bắt được trưởng thành ruồi vàng cao nhất 144,0 con/bẫy, thu bắt được trưởng thành bộ cánh vẩy cao nhất đạt 15,8 con/bẫy.

Trong vụ Thu - Đông, mồi dứa chín $10 \mathrm{~cm}$ và $5 \mathrm{~cm}$ có hiệu quả cao nhất, tiếp đó là mồi mít chín, cụ thể.

Mồi bẫy quả Dứa chín với độ dày $10 \mathrm{~cm}$ và $5 \mathrm{~cm}$ thu bắt trưởng thành ruồi vàng có hiệu quả cao nhất đạt 202,4 con/bẫy và 177,4 con/bẫy, thu bắt trưởng thành bộ cánh vẩy có hiệu quả cao nhất đạt 20,0 con/bẫy và 15,4 con/bẫy.

Mồi bẫy Mít chín có kích thước $10 \mathrm{~cm}^{2}$ thu bắt được trưởng thành ruồi vàng cao nhất 166,2 con/bẫy, thu bắt được trưởng thành bộ cánh vẩy cao nhất đạt 14,6 con/bẫy.

\section{REFERENCES}

[1] Department of Insects. (2004). Textbook on Specialized Insects. Hanoi Agricultural Publishing House.

[2] Ministry of Agriculture and Rural Development. (2014). Regulation 01-169: 2014 BNNPTNT on methods of investigating pests and diseases.

[3] Director of Department of Plant Protection. (2014). Regulation TCCS 119: 2014 / BVTV issued together with Decision No. 1236 / QD-BVTV-KH dated 31/7/2014. Regulations on investigation of pests and diseases for plants.

[4] Nhuong, N. H. (1996). Research on some biological characteristics, ecology and methods of breeding golden fly species in Ninh Thuan Nha Ho. 